Marquette University

e-Publications@Marquette

Economics Faculty Research and Publications

Economics, Department of

$12-1-2015$

Lawson on Veblen on Social Ontology

John B. Davis

Marquette University, john.davis@marquette.edu

Accepted version. "Lawson on Veblen on Social Ontology," in What is Neoclassical Economics?

Debating the Origins, Meaning and Significance. Ed. Jamie Morgan. New York: Routledge, 2015.

Publisher Link. (C) 2015 Taylor \& Francis (Routledge). Used with permission. 
Forthcoming in: What is this 'school' called neoclassical economics? Debating the issues, ed. Jamie Morgan, Routledge.

\title{
Lawson on Veblen on social ontology
}

\section{John B. Davis, Marquette University and University of Amsterdam}

\begin{abstract}
This paper discusses Lawson's use of Veblen's concept of 'neoclassical economics' and argument that the category of neoclassical economics should be jettisoned on the grounds that it obfuscates effective critique of mainstream economics. The paper links Lawson's critique of closed systems and Veblen's cumulative causation view by offering a reflexivity, feedback loop formulation of the latter aimed at overcoming the pre-Socratic dichotomy between Heraclitian and Parmenidean ontological thinking. The paper then reviews what this implies for three key social ontology doctrines: social reality as processual and highly transient; emergence and the appearance of novelty; the internal relatedness of social reality. Final remarks address the use of the 'neoclassical economics' concept.
\end{abstract}

Keywords: neoclassical economics, Veblen, Lawson, closed systems, cumulative causation, reflexivity

JEL code: B13, B41, B52

Acknowledgement: I am grateful to Steve Fleetwood, Wade Hands, Anne Mayhew, Robert McMaster, Nuno Martins, and Jamie Morgan for very helpful comments on a previous version of this chapter. 
Tony Lawson's "What is this 'school' called neoclassical economics?" draws on Thorstein Veblen's original use of 'neoclassical economics' to critically interpret contemporary employment of the term, and argue for jettisoning the category of neoclassical economics altogether on the grounds that its use obfuscates effective critique of mainstream economics (Lawson, 2013b; also cf. Lawson, 2003, pp. 184217). The looseness with which he believes the term and category have been generally applied has in his view allowed a whole range of disparate arguments about neoclassicism to compete for attention, resulting in a failure on the part of many commentators to see what is fundamentally problematic about mainstream economics. However, Veblen is hardly only valuable to Lawson because his initial conception of the term and category is an obvious starting point. His primary value resides in his evolutionary approach to science and associated critique of what he regarded as a primitive metaphysics of science particularly in the economics of his own time. Lawson regards this critique as close to his own critique of mainstream economics, and sees a discussion of Veblen's view of neoclassicism as an opportunity to refocus contemporary discussion about the nature of neoclassicism on its untenable metaphysical preconceptions. His arguments are specifically directed at self-identified heterodox economists, who in his view too often fail to see that the real source of economics' current problems lies not at the level of its substantive theorizing - that is, the content of economic doctrines - but at the level of methodology and social ontology - the study of the nature of social reality. Veblen used the term 'metaphysics' but the term 'ontology' has essentially the same meaning. In Lawson's language, then, the problem that Veblen identified remains the chief problem of mainstream economics today, namely, that it operates with a deficient social ontology. I am broadly sympathetic to this argument, and think that recourse to Veblen's evolutionary thinking is a helpful way to examine what is deficient in mainstream economics' social ontology. In this chapter I will attempt to contribute to their approach by further discussing some of the more important themes they emphasize.

\section{Lawson on Veblen}

Lawson's own social ontology critique of the mainstream is well known, but comparing Veblen's critique may cast additional light on it and perhaps further develop it as well. Let us begin with Lawson's recent statement of the argument. First, then, he argues that the near-universal practice in economics of approaching every question as an exercise in mathematical modeling reflects the mistaken presupposition that what gets modeled adequately captures the nature of the social realm. Specifically, such modeling assumes that the social world can be represented in terms of collections of event 
regularities which are stable and predictable - 'closed systems' as he labels them. Lawson denies, however, that the social realm can be represented in this way, and his reason for this points to his main ontological critique of mainstream. Secondly, then, he argues that, in order to apply their mathematical techniques, and thereby reason in closed system terms, the mainstream sees the social world in terms of event regularities, because in its associated worldview the 'stuff' that the world is made up of are isolated atoms. Atoms are not labeled as such for reasons of size, as the word suggests, but rather on account of their nature as isolated, unchanging entities. What specifically defines these entities' isolation and unchanging nature, then, is that they always have the same independent and invariable causal effects in their interaction with other atoms, whatever the context. It is this conception that thus underlies the mainstream supposing there exist stable and predictable event regularities in the world, which in turn underlies its commitment to mathematical modeling, which together give an ontological view that constitutes the real source of mainstream economics' failure as a discipline for Lawson.

This critique then tells us where to look if we are to develop a social ontology for economics adequate to its subject matter, and why Veblen plays a key role for Lawson. An ontologically 'open' world, Lawson argues, cannot be represented as a collections of event regularities, because the world cannot be made up of atoms exercising independent and invariable causal effects on one another. We can see why when we consider Veblen's evolutionary historical approach and alternative causal theory based on his idea of a cumulative causal sequence, an understanding Veblen emphasized is absent from neoclassical economics.

The prime postulate of evolutionary science, the preconception constantly underlying the inquiry, is the notion of a cumulative causal sequence .... Expressions of assent to this proposition abound. But the economists have not worked out or hit upon a method by which the inquiry in economics may consistently be conducted under the guidance of this postulate (Veblen, 1900, p. 266).

A cumulative causal sequence, or cumulative causation, is the idea that through positive feedback processes the operation of causality in the world continually feeds back upon and transforms the conditions on which causality operates, so that cause-effect relations must continually evolve and can never be constant, even if they appear to us to be nominally the same over time. Thus, since the things or entities occupying the world are subject to causal processes, it follows that just as cause-effect relations are continually being transformed, so these things or entities occupying the world must also be in continual transformation. The idea that atoms are the 'stuff' of the world is clearly inconsistent with 
this, and thus Lawson sees Veblen's conception as a fundamental contribution to anti-atomist reasoning about the social realm. Indeed, for him, Veblen's conception of an evolutionary historical world requires that the social world be seen as 'open.'

For both Lawson and Veblen, then, the social world is evolutionary and historical because it is continually being transformed. Further, an evolutionary historical approach to science rules out what Veblen termed a taxonomic approach to science, which is grounded in the assumption that the social realm is stable and unchanging, and which presupposes that the world is governed by regularities subject to classification in terms of 'normal' or 'natural' phenomena. A taxonomic approach is what Lawson sees as being involved in many current, even critical accounts of neoclassicism. Thus the problem he believes these accounts suffer from is that by referring to a neoclassical approach they implicitly make the debate a matter of which 'normal' phenomena economics ought to investigate, whereas what debate should rather focus upon is how we understand a social reality in which the phenomena do not have this character at all. Better, then, to simply abandon the term 'neoclassical' and work from the beginning with the idea that social phenomena unfold in an evolutionary way.

\section{A further look at Veblen's cumulative causation idea}

I agree, then, that Veblen's cumulative causation idea is an important contribution to philosophy of science, and that we need to understand and develop this core idea in order to explain how cause-andeffect relationships constantly evolve and explain the nature of the social realm. The basic idea cumulative causation employs is the non-identity of cause-effect sequences over time. In addition, Veblen allows for something in the way of similarity of cause-effect sequences over time, since as an evolutionary view cause-effect sequences at later times derive somehow from cause-effect sequences at earlier times. This means that the cumulative causation idea combines the concepts of non-identity and continuity, though while it is straightforward to state the first concept, the boundaries on the latter concept are difficult to explain in an evolutionary way. Let me attempt to illustrate this by giving a reflexivity interpretation of the cumulative causation idea, since reflexivity can be shown to be essential to at least the non-identity side of the idea.

Reflexivity is a property of human action in the social realm whereby there is a causal feedback loop between how the views people have of the future and the habits they sustain feed back on and influence what they do in the present, and how what they do in the present feeds forward on and 
influences their views and habits in the future. Thus in a reflexive social world, the influence of human action on cause-effect sequences means they can never be the same over time - the non-identity side of the idea - and the simple view of causality some have, where no feedback loops exist and the present strictly determines the future, as in the mainstream's invariable effects atomist ontology, must be rejected. Essentially, on a cumulative causation understanding, the so-called atoms are constantly evolving through the feedback loop process in virtue of agents continually acting on the conditions of action through time. Indeed, they cannot be atoms in the sense of unchanging entities. So reflexivity effectively explains the non-identity side of the cumulative causation idea. Yet Veblen's idea also allows for some notion of continuity in cause-effect sequences in the social realm. Let us then use this same feedback loop analysis to move from the non-identity side of the idea to this more difficult one by distinguishing two polar views of how continuity might be understood, and then using that distinction to lay out an intermediate ground to explain cumulative causation.

At one extreme, the continuity in both entities and cause-effect sequences might be thought so minimal as to be basically non-existent. I characterize this case as a Heraclitian world, after the pre-Socratic Greek philosopher Heraclitus of Ephesus. Heraclitus believed that change characterized everything (Panta rhei in Ancient Greek, meaning 'everything flows'), and is famous for expressing this in terms of the notion that one can never step into the same river twice. Yet Heraclitus was also a proponent of a 'unity of opposites' idea, which is manifest in the river image as well. That is, to be able to say one cannot step into the same river twice - his idea of all-encompassing change - one needs to presuppose the same river, albeit having the property of moving - the opposite of change. We can interpret this combination as a comment on the viability of this polar extreme as a reading of Veblen's continuity idea. In effect, if taken to this extreme, namely, as there being no continuity in the world whatsoever because all is change, the continuity concept becomes paradoxical and incoherent.

At the other extreme, a continuity in entities and cause-effect relations might be taken to the point of excluding change altogether. If we stay with the pre-Socratic world, the historic opponent of Heraclitus was Parmenides of Elea, who essentially argued that the concept of truth requires we say that nothing changes and change is only an appearance. On this view, truth implies that what is simply is and can never be but what it is. More fully, Parmenides' metaphysical-logical argument (using a kind of reductio indirect reasoning) was that what is must always have been the case, because if what is had ever not existed, it would have to have been in a state of becoming, and the concept of becoming is incoherent because it requires that something come out of nothing. But surely this view too is paradoxical, and 
accordingly neither should this polar extreme reading be seen as a viable way of interpreting Veblen's continuity concept.

How, then, can we use the reflexivity formulation of cumulative causation to interpret continuity in a way that gives us a characterization of the concept intermediate to these extremes? An advantage of a reflexivity formulation is that it is true to Veblen's emphasis on historical time. The feedback loop analysis, then, cannot be described without placing agents in time, or in effect by seeing them straddling time in that their actions always link the future and the present. What this implies, then, is that when agents change what they are doing in the present in light of their view of the future, they change what they are doing according to their understanding of how existing cause-effect sequences can be exploited to achieve their future goals, so that it is human action, understood reflexively, that creates continuity between non-identical cause-effect sequences across time. This role human action plays then gives us an interpretation of continuity for the cumulative causation idea in which change presupposes a stability about cause-effect in the present, and this stability simultaneously lays the basis for change in causeeffect sequences in the future. On this intermediate ground reading, then, neither polar extreme reading provides a tenable account of Veblen's cumulative causation idea, neither Heraclitus' all-ischange nor Parmenides' there-is-no-change. I suggest, then, that we employ this intermediate interpretation both as an explanatory tool for investigating the ontology of the social realm, and also to avoid polar extreme views of cause-effect sequences that might make the cumulative causation idea vulnerable to easy critique undermining its plausibility.

Returning to Lawson's critique of the mainstream ontological preconceptions, then, we find three positions he emphasizes a cumulative causation view implies about the nature of social reality: (1) it is processual and highly transient; (2) its phenomena are characterized by emergence and the appearance of novelty; (3) its phenomena are constituted in relation to one another, or the entities of the social world are internally related (Lawson, 2013b, p. 954). These ideas are all important for developing an alternative social ontology for economics, and in need of further discussion if we are to take Lawson's advice to stop talking about neoclassicism and focus on social ontology. I take them in order.

\section{Social reality as processual and highly transient}

Saying that social reality is processual and highly transient can be taken in two ways which may seem indistinguishable but are different. One can say it is the nature of social reality that it is processual and 
highly transient in itself or one can say it is a property of social reality that it is processual and highly transient. The former view is a Heraclitian one, and is inherently paradoxical. How can one refer to anything that constantly changes? There is no 'thing' one can refer to if that 'thing' is always different. The latter view that it is rather a property of social reality that it is processual and highly transient is what Heraclitus' own unity of opposites idea can achieve if we charitably read him as positing the river to be able to say you cannot step into it twice. Then one refers to the river as a single 'thing' to be able to ascribe to it the property of always moving. As a pre-Aristotelian, Heraclitus lacked the substanceproperty distinction, and thus employed the more awkward unity of opposites idea. However, Lawson inherits millennia of philosophical thinking, and can thus be fairly ascribed the view that a key property of social reality is that it is processual and highly transient rather than the view that social reality is in itself processual, as he seems to say in his paper.

If this seems an unnecessary semantic point, note that it implies, oddly perhaps given his emphasis on social reality being highly transient, that we can say what the unchanging nature of social reality is or what social reality always and necessarily is. Specifically, what social reality for Lawson is and always is a system of change, or in the terms he specifically employs to say this that include human action, social reality is and always is an agency/structure interaction in which agency and structure are each continually undergoing change and the relationship between agency and structure is also always undergoing change (e.g., Lawson, 2003, pp. 49ff). As I interpret how he has generally explained this idea across his writings, agency, a principle of human action, conditions social structures, which, as constituted out of social relationships, condition human action. My interpretation may not do justice to how Lawson understands this idea, but I believe it is sufficient to make my main point here, namely, that Lawson's idea that 'social reality is processual' is not the untenable, Heraclitian all-is-change polar extreme sort of view, despite his apparent statements to this effect, but rather the perhaps not best expression of his view that the given, unchanging nature of social reality itself is as an agency-structure interaction.

What follows from this is that while indeed it is a property of social reality that it is processual and highly transient, since this is what seeing the agency/structure pair as interaction requires, it is also - to put this in quite the opposite way - a property of social reality that it is recurringly stable and temporarily unchanging. That is, when we adopt an agency/structure interaction view, social reality has both the property of change and also the property of stability. While this may seem to simply introduce another paradox, it need not be taken this way. Indeed, Veblen's cumulative causation thinking works along just 
these lines without being paradoxical, since as an evolutionary view cause-effect sequences at later times derive from cause-effect sequences existing at earlier times. Earlier sequences are then in effect temporarily stable and at least for a time relatively unchanging since they provide the basis for change, and yet since later sequences are different, cumulative causation exhibits transience in cause-effect sequences as well. Put in terms of Lawson's agency/structure interaction view, human action presupposes social structures, so social structures must be stable enough to provide a basis for human action. Yet human action also transforms social structures, demonstrating their changing character. That is, as in Veblen's cumulative causation evolutionary historical view, so in Lawson's agency/structure model there is not only change but importantly also stability within a process of change. Thus we can confidently say that neither Veblen nor Lawson are Heraclitians!

Thus it is not accurate to simply say that social reality is processual and highly transient, as this is an incomplete characterization of the properties of social reality. I make this argument because it seems that the emphasis in "What is this 'school' called neoclassical economics?" is too strong on the side of social reality seen as changing and too weak on the side of social reality seen as in some manner unchanging. This is not just a philosophical point, because Lawson uses this emphasis to essentially rule out all mathematical modelling and including any event regularities in the domain of social ontology. For many heterodox economists, who are otherwise quite sympathetic to much of his argument, and who in many instances also hold an evolutionary understanding of social reality, this move ultimately renders Lawson's critique of the mainstream ineffective. Some critics charge his argument rules out all quantitative reasoning in economics. No doubt this is too strong, and Lawson denies he does. It is the modeling and exclusive recourse to event regularities that is the problem. But where is the line between use of quantitative reasoning and mathematical modeling? I make no attempt to revisit this debate, and only note that it is clearly hard to discuss substantive theorizing in economics (the doctrines we discuss) if social reality is seen purely as processual and highly transient. What would one refer to if what one refers to is not what it is because it has already changed? This would then leave critical theory isolated within the space of methodology.

So it is tempting to conclude that the emphasis in this current reading of Veblen represents a step back from his agency/structure interaction analysis, and is not helpful to the interpretation of Veblen either. However I withhold this judgment, because Lawson has things to say about emergence and internal relations in the social world that gives us both a different view of his argument and more weight to his agency/structure interaction thinking. 


\section{Emergence and the appearance of novelty}

The concept of emergence is fundamental to an alternative social ontology since it requires rejection of the mainstream economics idea that social reality is constituted out of atoms that always have the same independent and invariable causal effects in their interaction with other atoms, whatever the context. If the stuff of social reality always works in the same invariable way, there can be nothing new or novel in the world, and science then becomes a taxonomic exercise in the classification of 'normal' or 'natural' phenomena. Emergence is also intrinsic to the idea that a fundamental property of social reality is change, since the concept is defined by the idea that what emerges is not reducible to that from which it emerges. That is, emergent or novel phenomena are 'emergent upon' phenomena to which they are related but which cannot fully explain them. Further, the concept of emergence is fundamental to the agency/structure model since agency and structure constitute two different dimensions of social reality that condition one another, so that each must be emergent upon the other.

In "What is this 'school' called neoclassical economics?" then, Lawson says that social reality is "an emergent phenomenon of human interaction" (Lawson, 2013b, p. 954). It seems it should be that social reality is an emergent phenomenon of agency/structure interaction, though it may have been intended that 'human interaction' means 'agency/structure interaction.' Thus, if we describe the agency/structure interaction in a reflexive way in terms of feedback loops, we would say that people act with an expectation of the future together with an understanding of the nature of their actions and their possible consequences as conditioned by social structures, and that the effects of their actions in the present then condition the evolution of social structures. Thus both human action and social structures are emergent upon one another. Similarly, when we think of change in Veblen's cumulative causation terms, an historical evolution of cause-effect sequences exhibits emergence in that cause-effect sequences at later times are emergent upon cause-effect sequences of earlier times in the sense that the former are related to but not fully explainable in terms of the latter.

Emergence is thus fundamental to agency/structure reasoning and cumulative causation, but how can the idea actually be explained, given critiques of the idea dating back as far as Parmenides which argue that emergence essentially means that something comes out of nothing. Lawson's strategy, then, is to explain emergence in terms of different levels of social reality and how entities combine across them. 
An emergent entity ... is usually found, or anyway held, to be composed out of elements deemed to be situated at a different (lower) level of reality to itself, but which have (perhaps through being modified) become organised as components of the emergent (higher level) entity or causal totality. 'Emergence', then, as widely interpreted is ultimately a compositional term and involves components being organised rather than aggregated (Lawson, 2013b, p. 954n, emphasis added; also cf. 2003, pp. 43-4, and Lawson 2013a).

Clearly there is a metaphorical quality to this reference to higher and lower levels, since the evolution of social reality for Veblen or Lawson does not really occur in any sort of Euclidian spatial framework, and I accordingly recommend that this language be set aside or used with proper caveats. More work is done in explaining the concept, however, in the comparison between the different ways in which components of entities get combined, with the difference being between when they are organized and result in emergent entities versus when they are aggregated without resulting in emergent entities. However, the difference between these cases is not immediately clear, because an aggregation of a set of components is also an organization of them. So clearly Lawson has a particular kind of organization in mind. What is it?

As a first pass, we can use the idea of organic connection to say that emergent entities are somehow 'more than the sum' of their components, thus not reducible to them, thus emergent upon them. To make this conception persuasive, we would need to be able to distinguish it from non-emergent entities whose components are merely aggregated are not 'more than the sum' of their components. Yet the 'more than the sum' idea is vulnerable to the eyes of the beholder problem. An aggregation of a set of components is not organic for Lawson, but another person might see this producing a novel entity if the aggregation was new to them and served some distinct purpose. Then a non-organized entity would also be an emergent one, and the idea of being organized loses its leverage. Putting aside the eye of the beholder problem, even aggregated entities, taking the meaning of aggregation to be that they are additively assembled, can be irreducible to their components, as in the famous sand pile example (Bak, Tang, and Wiesenfeld, 1987). As grains of sand are added to a pile of sand, at some transition point the pile collapses, so it follows that the pile has a property over and above its character as an aggregation of sand grain components. Thus it is not clear what distinguishes organization and aggregation. One might then just abandon the distinction and say that all combinations of components produce novel, emergent entities. But this strategy faces the problem of telling us why combination generates something novel and emergent. Might not the disorganization of an entity produce something novel and emergent? 
Then we run the risk of being pushed to the conclusion that everything is emergent, and the term collapses simply on the results of change.

I suggest, then, we rather adopt a Veblenian reflexivity defense of emergence in virtue of how a reflexivity analysis works through the property of self-referentiality. Thus, when we explain cumulative causation we say that the operation of causality in the world continually feeds back upon and transforms the very conditions on which causality operates, and that cause-effect relations continually evolve and are never constant because of this. A cumulative causation process is self-referential, then, in the sense that it references and operates upon itself, and in virtue of this continually changes its own components, thereby securing novelty through time. In contrast, with aggregation the aggregated entity does not act on the character of its components. In the sand pile example, the sand grains are not changed in themselves by their aggregation, including if the pile collapses or otherwise changes its character. In effect, they are like Lawson's atoms, invariable and constant in their effects in combination with one another. Thus, however they are piled, there is nothing ontologically novel and emergent in this as compared to what occurs in a self-referential process in which entities that combine components always change their components. To defend emergence, then, I believe we need to understand process reflexively in this way, whether in connection with a Veblenian evolutionary model or in connection with the agency/structure interaction model. As noted above, what a reflexivity analysis does is make time intrinsic to explaining the phenomena of the social realm; that is, make our explanation truly historical. Time is absent from the organization-aggregation argument for emergence, so that argument seems vulnerable to being simply a taxonomic strategy without genuine causal dimensions. With this in mind, let us turn to the last topic, the internal relatedness of social reality.

\section{The internal relatedness of social reality}

Lawson emphasizes that the internal relatedness of social reality grounds the place of emergence in an alternative social ontology.

Furthermore, social reality is found to be composed of emergent phenomena that (far from being isolatable) are actually constituted in relation (that is, are internally related) to other things, and ultimately to everything else (for example, students and teachers, qua students and teachers, are constituted in relation to each other; so are employers and employees, ... and so 
forth). Constitutive social relations in short are a fundamental feature of social reality. (Lawson, 2013, pp. 954-5).

Emergent phenomena, then, are emergent upon social relatedness, as in the student-teacher example. Students and teachers are what they are only in relation to one another. If they are what they are in some way apart from their relation to one another, they would be externally rather than internally related. Were they externally related, they would be like atoms, acting as their natures determined irrespective of the context of interaction. So internal relatedness is comprehensive, as it were, of the things related. This means that since the things related internally are still distinguishable - students and teachers are still different from one another - there is something over and above them being the different types of entities they are that explains their difference. What is over and above them, then, is emergent upon their difference. Emergence, then, is an intrinsic characteristic of the internal relatedness of the world.

This argument works best, one can see, with pair-wise relations, because it is plausible that the things paired, say, students and teachers, lack meaning apart from their relation to one another. What is a teacher but a teacher of students? The argument is less clear when non-pair-wise relations come into play. What is the relation of student to employer? By the standard of internally related student-teacher pair, it seems student and employer are externally related. Arguments to the effect that student and employer are ultimately internally related through some chain of pair-wise relations are strained and on the surface implausible, if only because the standard of internal relatedness is the close connection of cases such as student and teacher. The back-up argument would be to say something like, everything under capitalism is internally related, using the 'under capitalism' expression as a systemic internal relation device. Yet this argument is sufficiently tendentious as to be little more than a way of assuming the conclusion, where those who are candidates to accept it simply share a broad-based desire to see capitalism as being at the root of everything.

It seems more reasonable to conclude, then, that not all things are internally related (as no doubt Lawson also believes). At least the burden of argument should rest on those who suppose they are. Another possible problem with internal relatedness I think can be set aside. If the meanings and nature of student and teacher are not fully but only partially exhausted by their relation to one another (a kind of hybrid relationship), their degree of internal relatedness could still be argued to support emergent phenomena. So we would still be entitled to say that a world in which internal relatedness is in some 
degree constitutive of social reality that we have elements of a way of understanding emergence. I say 'elements' for two reasons.

First, because though we can see the outline of the argument that the comprehensiveness of an internal relation generates phenomena over and above what we know about what it relates, the claim that these phenomena are novel and emergent remains to be demonstrated persuasively. Above, I have already argued that the 'more than the sum' organicism idea is not likely to do the job. But there is another perhaps more serious problem in explaining emergence in terms of internal relations: if what constitutes the phenomena to be judged to be emergent is the highly related nature of the entities related, why should the constituted phenomena even be regarded as emergent and novel? Why aren't any 'new' phenomena already comprehended under the relatedness of the entities? In effect, why should there be anything new under a sun that shines so brightly? Granted, this is a skeptical argument, and skeptical arguments should be sometimes dismissed out of hand. But I pose this argument nonetheless because the connection between internal relatedness and emergence has not been set out beyond the language of things being constituted together.

Second, then, I say there are 'elements' of an argument here for emergence, because the case has been made entirely on the structural side of the agency/structure analysis in terms of relations as if agency and human action plays no role and can be ignored. In defense of Lawson, he does emphasize human practice when he argues for a processual conception, so we should assume that he is thinking in terms of agency/structure interaction as in his earlier writings. In my view, however, the self-referentiality argument I gave in the last section about how to justify emergence through a reflexivity interpretation of Veblen and the agency/structure view still holds. The self-referentiality it depends upon only explains emergence by supposing agents operate on what in effect are the conditions of their own agency, namely, social structures. Just as for Veblen, causality is cumulative because the operation of causality in the world transforms the conditions of causality, so in agency/structure interaction emergent phenomena exist because agents' action continually transform the social structures that condition action.

The risk of minimizing action and agency is that one's vision of social reality can then veer toward becoming an entirely relational one, as in the position advanced by F.H. Bradley (1893), a neo-Hegelian proponent of view that 'all relations are internal.' A particular problem with this approach is that once one sees everything as internally related, one is likely to adopt the viewpoint of the whole, and be left pitching one's arguments in terms of systems and social totalities. Then again, everything (and nothing) 
ends up being novel and emergent. In contrast, the advantage of the agency/structure interaction approach is it includes a principle not reducible to relations, that is, the principle of action. By nature, action changes the world and so generates emergent phenomena. The world may well still be highly internally related as Lawson claims. Yet that agency influences structure can also be disruptive of systems of internal relations, as when employees reject or resist hierarchical power arrangements in their relations with employers. I conclude, then, that it the idea that social reality is highly internally related is important to an alternative social ontology, but that this idea needs to be used in a measured way that recognizes not only the importance of human action but also the diversity of relational forms.

\section{"What is this 'school' called neoclassical economics?"}

Lawson concludes his paper by saying that in modern economics there is a "basic tension between ontology and method ... that hinders serious attempts to overcoming the real problems of the discipline" (Lawson, 2013, p. 979). If the mainstream method is that of mathematical modeling and event regularities and its implicit ontology is that of atoms constantly exercising invariable effects, then this thesis seems confusing since mainstream method and ontology rather appear to mutually support one another, as I interpreted Lawson's argument at the outset. If there were evidence of any commitment to an evolutionary ontology in the mainstream, it would indeed make sense to say there exists a tension between method and ontology. But I see very few mainstream economists entertaining any sort of evolutionary historical thinking, and most are fully committed to mathematical modeling. I agree, following Veblen, that this makes mainstream economics what he calls a taxonomic science dedicated to identifying 'natural' and 'normal' relationships. Thus the rise of behavioral economics can simply be interpreted as the investigation of previously unexplored 'natural' and 'normal' relationships. I also agree that the method and ontology of the mainstream has hindered the development of the discipline. But what rather seems to hinder the development of the discipline is the lack of tension between method and ontology in mainstream economics.

Veblen coined the term 'neoclassical' to classify all forms of economics that failed to adopt an evolutionary historical approach and settled for being a taxonomic one. Since this seems to continue to characterize the mainstream today, the implication seems to be that we should retain his usage instead of jettisoning the term. I am sympathetic to Lawson's desire to shift discussion from what neoclassicism is substantively to the project of developing an alternative evolutionary social ontology, though this 
does not mean substantive critique should be overlooked. But it may better serve that goal to emphasize what the social ontology of the mainstream is, flagging it as neoclassical, and emphasizing the interlocking nature of its ontology and method. Bringing Veblen's approach into the foreground seems to be an appropriate way to make a sharp distinction between the evolutionary and neoclassical method-ontology approaches.

This then raises an interesting issue for heterodox economics, Lawson's ultimate target in his paper. His concern seems to be that many heterodox economists ostensibly reason in a non-evolutionary way or taxonomically, simply posing their preferred 'natural' and 'normal' relationships (e.g., provisioning) as

alternative to mainstream ones (e.g., efficiency). But in fairness, I believe many heterodox economists who are not explicit about evolutionary processes are would be seen to be committed to evolutionary ontologies when pressed. So, in contrast to neoclassical method and ontology that line up, heterodox economists are indeed at risk of involving themselves a "tension between ontology and method" Lawson attributes to the mainstream. I would only suggest that the tension he sees in heterodoxy is not as basic as the one he attributes to the mainstream. One of the defining characteristics of heterodox economics (cf. Davis, 2008, p. 360), I suggest, is to reason relationally in agency/structure terms. Surely this presupposes an evolutionary view of the world.

\section{References}

Bak, Peter, Chao Tang and Kurt Wiesenfeld (1987) "Self-organized criticality: An explanation of 1/f noise," Physical Review Letters 59 (4): 381-384.

Bradley, F.H. (1893) Appearance and Reality, Oxford: Clarendon Press.

Davis, John (2008) "The turn in recent economics and return of orthodoxy," Cambridge Journal of Economics 32, 349-366.

Lawson, Tony (2013a) “Emergence, morphogenesis, causal reduction and downward causation," in M. Archer, ed., Social Morphogenesis, New York: Springer: 61-84.

Lawson, Tony (2013b) "What is this 'school' called neoclassical economics?" Cambridge Journal of Economics 37: 947-983.

Lawson, Tony (2003) Reorienting Economics, London: Routledge. 
Veblen, Thorstein (1900) "The Preconceptions of Economic Science III, Quarterly Journal of Economics 14 (2): 240-269. 